\title{
LOS CONFLICTOS ENTRE LIBERTADES ECONÓMICAS Y DERECHOS FUNDAMENTALES EN LA JURISPRUDENCIA DEL TRIBUNAL DE JUSTICIA DE LA UNIÓN EUROPEA
}

JOAQUÍN SARRIÓN ESTEVE 


\section{SUMARIO}

1. INTRODUCCIÓN. 2. DELIMITACIÓN Y ESTUDIO DE LOS CASOS DE CONFLICTO. 2.1. Conflictos indirectos. 2.2. Conflictos directos. 2.2.1. El «énfasis constitucional». 2.2.2. La tutela de los derechos sociales. 3. CONCLUSIONES. 


\title{
LOS CONFLICTOS ENTRE LIBERTADES ECONÓMICAS Y DERECHOS FUNDAMENTALES EN LA JURISPRUDENCIA DEL TRIBUNAL DE JUSTICIA DE LA UNIÓN EUROPEA
}

POR

\author{
JOAQUÍN SARRIÓN ESTEVE
}

Doctor en Derecho por la Universidad de Bolonia, Investigador UNED.

\section{INTRODUCCIÓN}

Como es sabido, mientras que en un primer momento los Tratados constitutivos de las Comunidades Europeas guardaban silencio sobre la protección de los derechos fundamentales, ${ }^{1}$ las cuatro libertades económicas fundamentales han gozado

${ }^{1}$ Sin entrar en la cuestión del concepto de «derechos fundamentales» y su distinción con el de «derechos humanos», debemos precisar que utilizamos el de «derechos fundamentales» que es el común en el ámbito del Derecho de la Unión Europea por sus peculiaridades. Vid. DIEZ PICAZO, L.M. (2005). Sistema de derechos Fundamentales, Madrid, Civitas, $2^{\mathrm{a}}$ edición, p. 389; Para un estudio más profundo del concepto remitimos a: BOBBIO, N. (1991). El tiempo de los derechos, Madrid, Sistema; ALEXY, R. (1993). Teoría de los derechos fundamentales, Madrid, CEPC; PÉREZ LUÑO, A.E. (1997). Los derechos fundamentales, Madrid, Tecnos; TORRES DEL MORAL, A. (2007). «Fundamento, naturaleza y sujeto de los derechos», en Los derechos fundamentales y su protección jurisdiccional, Madrid, Colex. 
siempre de un lugar privilegiado en los Tratados, pues servían de instrumentos al servicio de la consecución del mercado y la integración económica europea. ${ }^{2}$

Pero el desarrollo de la Jurisprudencia del Tribunal de Justicia en un primer momento, y posteriormente las sucesivas reformas de los Tratados han abierto un escenario en el que los derechos fundamentales han ido adquiriendo una relevancia progresivamente superior en la Unión Europea (UE); ${ }^{3}$ que terminaría por producir una colisión entre éstos y las libertades económicas. ${ }^{4}$

Si estudiamos los casos en los que el Tribunal de Justicia ha relacionado ambas categorías (libertades económicas y derechos fundamentales) podemos encontrar dos tipos de relación o interacción: una positiva o de apoyo; y otra negativa o conflictual. ${ }^{5}$

En el primer tipo de relación, la sentencia más representativa es la conocida Elliniki o ERT (1991) $)^{6}$ en la que el Tribunal de Justicia afirmó que los Estados miembros deben respetar los derechos fundamentales cuando aplican el Derecho comunitario, siendo dicho respeto exigible también cuando se trata de establecer excepciones a las obligaciones de los Tratados. Así, un Estado miembro a la hora de tomar medidas que restrinjan una libertad económica fundamental no sólo debe te-

${ }^{2}$ De hecho, estas libertades constituyen el fundamento del mercado. Vid. Art. 26.2 Tratado de Funcionamiento de la Unión Europea (TFUE). Actualmente las cuatro libertades están reguladas: libre circulación de mercancías (arts. 28.1 y 30 TFUE); la libre circulación de trabajadores (art. 45 TFUE); la libre prestación de servicios (arts. 49 y 56 TFUE); y la libre circulación de capitales (art. 64 TFUE). Para un estudio profundo vid. PÉREZ DE LAS HERAS, B. (2008). El Mercado Interior Europeo. Las libertades económicas comunitarias: mercancías, personas, servicios y capitales, Bilbao, $2^{a}$ edición, Universidad de Deusto.

3 Quizá podríamos afirmar que tras la entrada en vigor del Tratado de Lisboa y la adquisición por parte de la Carta de los Derechos Fundamentales de la Unión Europea de una fuerza jurídica equivalente al Tratado se ha abierto finalmente un nuevo «horizonte constitucional» en la Unión Europea. SARRIÓN ESTEVE, J. (2011). «El nuevo horizonte constitucional para la Unión Europea: a propósito de la entrada en vigor del Tratado de Lisboa y la Carta de los Derechos Fundamentales», Ceflegal Revista Práctica de Derecho, n. 121, pp. 53-111,

${ }^{4}$ Quizá podemos encontrar un punto de inflexión en la sentencia Kreil (2000), dictada con poca antelación a la aprobación de la Carta (Sentencia de 11 de enero de 2000, Tanja Kreil, asunto C-285/98). CARTABIA la considera «the forerunner of the new line of decisions of the European Court on human rights». Vid. CARTABIA, M. (2009). «Europe and Rights: Taking Dialogue Seriously», European Constitutional Law Review, v.5, n.1, 2009, p. 9.

5 KRZEMINSKA-VAMVAKA J. (2005). «Free speech Meets Free Movement - How fundamental really is "Fundamental"? The Impact of Fundamental Rights on Internal Market Law», ZERP-Diskussionspapier, n. 3, http://ssrn.com/abstract $=1134809$, p. 7.

${ }^{6}$ Sentencia de 18 de junio de 1991, Elliniki Radiophonia Tiléorassi AE et Panellinia Omospondia Syllogon prossopilou v. Dimotiki Etairia Pliroforissis et Sotirios Kouvelas et Nicolaos Avdellas y otros, asunto C-260/89. 
ner en cuenta que esta restricción debe estar justificada, como venía exigiendo la jurisprudencia del Tribunal, sino que debe también respetar los derechos fundamentales reconocidos como principios generales del Derecho comunitario. ${ }^{7}$

Si bien se criticó la utilización o instrumentalización de los derechos fundamentales al servicio del mercado y sus libertades fundamentales; ${ }^{8}$ a nuestro entender en la sentencia tanto derechos fundamentales como libertades del mercado encuentran un vínculo de carácter positivo. ${ }^{?}$

Pero lo más relevante, desde el punto de vista de la protección de los derechos fundamentales, es aproximarse al segundo tipo de relación, es decir, la relación de conflicto, y estudiar cómo el Tribunal de Justicia pondera entre libertades económicas y derechos fundamentales.

A la hora de estudiar estos casos de conflicto consideramos que cabrían dos aproximaciones por parte del Tribunal de Justicia, cada una de las cuales supondría la asunción de una premisa: la existencia o no de una relación jerárquica en el estatus de las libertades fundamentales del mercado interno y de los derechos fundamentales: ${ }^{10}$

a) Existencia de una relación jerárquica

Si existe una relación jerárquica entre ambas categorías la relación podría ser favorable a las libertades del mercado o bien favorable a los derechos fundamentales.

Dentro de esta aproximación, en caso de que el mayor estatus correspondiera a las libertades económicas, la subordinación de los derechos fundamentales se

7 JACOBS, F.G. (2001). «Human Rights in the European Union: the role of the Court of Justice», European Law Review, 4, pp. 331-337.

8 BIONDI, A. (2004). «Free Trade, a Mountain Road and the Right to Protest: European Economic Freedoms and Fundamental Individual Rights», European Human Rights Law Review, v.9, n. 1, p. 55; COPPELL, J., y O'NEIL, A. (1992). «The European court of Justice: Taking Rights Seriously?», Common Market Law Review, v. 29, n. 4, p. 689; y PERIŠIN, T. (2006). «Interaction of fundamental (human) rights and fundamental (market) freedoms in the EU», Croatian Yearbook of European Law and Policy, v.2 , p. 73

9 La línea comenzada en Elliniki habría sido muy relevante, aplicándose tanto en materia de libre circulación de mercancías en relación con la libertad de expresión en la sentencia Karner (de 25 de marzo de 2004, Herbert Karner Industrie-Auktionen GmbH c. Troostwijk GmbH, asunto C71/02), como también en materia de libre circulación de personas y trabajadores en relación con el derecho a la vida familiar en la sentencia Carpenter (Sentencia de 11 de julio de 2002, Mary Carpenter c. Secretary of State for the Home Department, asunto C-60/00).

10 BROWN, C. (2003). «Case note- Case C-112/00 Eugen Schmidberger, Internationale Transporte und Pflanzüge v. Austria, Judgmenet of 12 June 2003, Full Court», Common Market Law Reivew, v. 40, n.6, pp. 1507-1508; GONZALES, G. (2004). «EC Fundamental Freedoms v. Human Rights in the Case C-112/00 Eugen Schimidberger v. Austria, [2003], ECR I-5659», Legal Issues of Economic Integration, v. 31, n. 3, pp. 219 y 226; PERIŠIN, T. op. cit. p. 86. 
manifestaría en la constitución por parte de los mismos de restricciones a las libertades o excepciones a las obligaciones derivadas de los Tratados que podrían, en función de las circunstancias, estar justificadas.

Pero tras este razonamiento hay dos posibilidades: 1) cabría entender que los derechos fundamentales pudieran formar parte de las justificaciones previstas de forma expresa en el Tratado; 2) o bien que los derechos fundamentales constituyen mandatos imperativos (mandatory requirements) que pueden justificar restricciones a las libertades económicas fundamentales. En ambos casos el punto de partida sería la consideración de las libertades fundamentales como la regla general, que podrían excepcionar los derechos fundamentales.

Ahora bien, si se razona que son los derechos fundamentales los que gozan de un mayor estatus, entonces las libertades económicas fundamentales sólo pueden aplicarse en función y de conformidad con los derechos fundamentales. ${ }^{11}$

b) Ausencia de relación jerárquica

Si entendemos que no existe una relación de jerarquía, sino que libertades económicas y derechos fundamentales ostentan un estatus equivalente en el Derecho de la Unión Europea, entonces los derechos fundamentales no pueden constituir una mera excepción a las obligaciones derivadas de los Tratados, sino que su protección o tutela supone una realización del Derecho de la UE, y a la hora de restringir las libertades económicas fundamentales para proteger los derechos fundamentales los Estados miembros estarían aplicando el Derecho de la Unión. ${ }^{12}$

En este trabajo vamos a tratar de identificar y delimitar los casos de conflicto referidos para poder estudiar la solución que adopta el Tribunal en cada uno de ellos, y verificar qué aproximación realiza y si es posible extraer una doctrina general en relación a la resolución de los conflictos entre libertades económicas y derechos fundamentales.

\section{DELIMITACIÓN Y ESTUDIO DE LOS CASOS DE CONFLICTO}

Entendemos que existe un caso de conflicto entre una libertad económica y un derecho fundamental cuando en una sentencia se resuelve un enfrentamiento entre ambas categorías o intereses en juego, y el Tribunal de Justicia da una respuesta que, de una manera u otra, favorecerá a uno de los dos.

11 Vid. PERIŠIN, T. op. cit., p. 85.

12 MORIJIN, J. (2006). «Balancing Fundamental Rights and Common Market Freedoms in Union Law: Schmidberger and Omega in the Light of the European Constitution», European Law Journal, n. 15, pp. 31-33 
En el estudio llevado a cabo hemos localizado una serie de casos o supuestos de conflicto que han sido resueltos por el Tribunal de Justicia. ${ }^{13}$ Entre ellos se puede diferenciar entre conflicto indirectos y conflictos directos (o de conflicto en sentido estricto).

\subsection{Conflictos indirectos}

Podríamos considerar conflictos indirectos aquellos supuestos en los que la colisión entre libertades económicas y derechos fundamentales se produce de una forma velada, de tal manera que el derecho fundamental que entra en juego lo hace en conexión con otro valor que es el que realmente se enfrenta a la libertad económica fundamental, y si bien podríamos hablar de un conflicto, entendemos que es susceptible de ser calificado como indirecto. Los casos más representativos serían los resueltos en las sentencias Familiapress (1997) ${ }^{14}$ y United Pan-Europe (2007). ${ }^{15}$

En Familiapress el Tribunal de Justicia se ocupa de estudiar la conformidad con el Derecho comunitario de una normativa austríaca que prohibía la venta de publicaciones en las que se pudiera participar en juegos con premios cuando no fueran publicaciones nacionales. El objetivo que perseguía esta legislación era preservar los pequeños periódicos nacionales y la pluralidad de prensa.

Podemos apreciar un conflicto entre la libre circulación de mercancías y el pluralismo de prensa, constituyendo este último el motivo justificativo de la restricción a la libertad económica fundamental, y que está conectado al derecho fundamental a la libertad de expresión. Estaríamos pues ante un conflicto entre una libertad económica fundamental y un derecho fundamental, aunque sea de forma indirecta. ${ }^{16}$

13 PERIŠIN, T. op. cit., p. 85.

14 Nótese que en algunos casos en los que podría considerarse la existencia de un conflicto entre libertades económicas y derechos fundamentales, no han sido resueltos en este sentido. Vid. las Sentencias de 4 de octubre de 1991, S.P.U.C c. Grogan, asunto C-159/90 (entre la libre prestación de servicios y el derecho a la vida del nasciturus reconocido en la Constitución irlandesa); de 15 de diciembre de 1995, Bosman, asunto C-415/93 (entre la libre circulación de trabajadores y el derecho de asociación); y de 9 de diciembre de 1997, Comisión c. Francia, asunto C-265/95 (entre la libre circulación de mercancía y el derecho de manifestación)

15 Sentencia de 26 de junio de 1997, Vereinigte Familiapress Zeitungsverlags-und vertriebs GmbH v. Heinrich Bauer Verlag, asunto C-368/95.

16 Sentencia de 13 de diciembre de 2007, United Pan-Europe Communications Belgium SA y otros c. Bélgica, asunto C-250/06. 
Sin embargo, hay que tener en cuenta que también podría verse afectada la libertad de expresión al producirse una restricción de la circulación de publicaciones no nacionales, y por tanto jugar, en este sentido, el derecho fundamental a la libertad de expresión a favor de la libre circulación de mercancías. ${ }^{17}$

El Tribunal de Justicia entendió que el objetivo que perseguía la legislación austríaca podía justificar la restricción de la libre circulación de mercancías, si bien utilizaba el test de proporcionalidad. De esta forma, exigía que la medida restrictiva debía ser adecuada para realizar el objetivo perseguido y la menos restrictiva posible entre las que se pudieran adoptar, debiendo respetar los derechos fundamentales, y dentro de los mismos la libertad de expresión, recogida en el art. $10 \mathrm{CEDH}$. El Tribunal concreta que este derecho permite limitaciones con la finalidad de mantener la diversidad de prensa siempre que estén previstas en la ley y sean necesarias en una sociedad democrática. ${ }^{18}$ En cualquier caso, no resolvía la cuestión, y la dejaba en manos del juez nacional, dejando por tanto un margen de apreciación nacional.

En United-Pan-Europe, una normativa belga imponía a los distribuidores autorizados a explotar una red de tele-distribución en la región de Bruselas la obligación de trasmitir una serie de programas difundidos por organismos de radiodifusión que dependían de la Comunidad francesa y la flamenca. Esta normativa se había adoptado con el objetivo de salvaguardar el pluralismo y el acceso a la cultura de las comunidades lingüísticas de la capital de Bélgica. El Tribunal de Justicia tenía que resolver si la imposición de esta obligación de transmisión de programas podía suponer una restricción a la libre prestación de servicios y ser contraria al Derecho comunitario.

El Tribunal de Justicia consideró que esta normativa constituía, en efecto, una restricción a la libre prestación de servicios, pero quedaba justificada. Dicha justificación se sustentaba en el mantenimiento del pluralismo, que asociado a la libertad de expresión era un objetivo legítimo a perseguir. Por tanto, la medida podía ser adecuada para alcanzar dicho objetivo en una comunidad bilingüe como la de Bruselas, al garantizar a los miembros de ambas comunidades lingüísticas el acceso a los programas de sus respectivas culturas.

No obstante, dejaba la aplicación del test de proporcionalidad al órgano jurisdiccional belga, tal y como había hecho también en el asunto Familiapress.

17 PERIŠIN, T. op. cit., p. 75.

18 LINDFELT, M. (2007). Fundamental Rights in the European Union - Towards Higher Law of the Land? A Study of the Status of Fundamental Rights in a Broader Constitutional Setting, Åbo, Åbo Akademi University, p. 211; BARNARD, C. (2007). The substantive law of the EU, Oxford, Oxford University Press, p. 188. 
Ahora bien, establecía que la medida restrictiva no debía ser desproporcionada ni debía entrañar discriminaciones a los no nacionales; y los procedimientos de selección de los programas de retransmisión obligatoria debían ser transparentes y con criterios claros y precisos.

\subsection{Conflictos directos}

A diferencia de los casos de conflicto indirecto, en los conflictos directos el derecho fundamental que interviene colisiona por si mismo frente a la libertad económica fundamental.

El Tribunal de Justicia comienza a resolver conflictos directos ponderando libertades económicas y derechos fundamentales en la sentencia Schmidberger (2003), ${ }^{19}$ donde se tutela el derecho a la libertad de expresión y de reunión y que constituiría la primera de una serie de sentencias que muestran un «énfasis constitucional» por parte del Tribunal de Justicia en la tutela de los derechos fundamentales, ya que, éstos prevalecen frente a las libertades económicas. Responderían también a dicho énfasis las sentencias Omega $(2004)^{20}$, donde tutela la dignidad humana frente a la libre prestación de servicios; también tendríamos la sentencia Sayn Wittgestein (2010) ${ }^{21}$ pero en esta ocasión lo que se tutela es principio de igualdad frente a la libre circulación. ${ }^{22}$

Por otro lado, encontramos también una serie de supuestos en los que el Tribunal de Justicia pondera entre libertades económicas fundamentales y «derechos sociales» o quizá más precisamente derechos sociales-laborales. ${ }^{23}$ Así, en las sentencias Viking (2007) ${ }^{24}$ y Laval (2007) el Tribunal resuelve un conflicto entre el

19 Apartado 26 de la sentencia. Lo hace con cita de la sentencia del TEDH, de 24 de noviembre de 1993, Inormationsverein Lentia and others c. Austria.

20 Sentencia de 12 de junio de 2003, Eugen Schmidberger, Inernationale Transporte und Planzüge, asunto C-112/00.

21 Sentencia de 14 de octubre de 2004, Omega, asunto C-36/02.

22 Sentencia de 22 de diciembre de 2010, Ilonka Sayn-Wittgenstein c. Landeshauptmann von Wien, asunto C-208/09.

${ }^{23}$ Este caso es singular pues en el conflicto intervienen por un lado la libre circulación de personas y algunos derechos fundamentales como el derecho a la vida privada y familiar frente al principio constitucional de igualdad y la identidad constitucional de la República de Austria.

${ }^{24}$ Utilizamos la expresión «derechos sociales» en un sentido amplio, y refiriéndonos a los derechos laborales, tal y como viene haciendo la doctrina, y el propio Tribunal de Justicia. Vid. FUDGE, J. (2007). «The new discourse of lavour rigths: from social to fundamental rights», Comparative Labor Law Policy Journal, v. 29, n.1, pp. 29-66; RODRÍGUEZ PIÑERO-ROYO, M. (2009). «Libertades económicas y derechos sociales en la Unión Europea», XX Congreso Nacional 
derecho a la acción colectiva y la libre prestación de servicios; y en la sentencia Comisión c. Alemania (2010) ${ }^{25}$ resuelve un conflicto entre el derecho a la negociación colectiva y las libertades de establecimiento y libre prestación de servicios. Debemos diferenciar estos supuestos de otras tras sentencias en las que la cuestión a resolver es si la protección de los trabajadores puede justificar una restricción a una libertad económica, pero entendemos que no se produce una colisión, en sentido estricto, entre una libertad económica y derechos fundamentales: ${ }^{26}$ Rüffert (2008), ${ }^{27}$ Comisión c. Luxemburgo (2008), ${ }^{28}$ y Santos Palbota (2010) ${ }^{29}$

\subsubsection{El «énfasis constitucional»}

b) La tutela de los derechos de expresión y reunión: Schmidberger (2003)

Una asociación medioambiental, llamada «Transitforum Austria Tirol», preocupada por los efectos del transporte pesado de mercancías llevó a cabo una concentración en la importante autopista austríaca de Brenner, principal ruta de acceso a Italia. Esta concentración había sido autorizada por las autoridades y se habían buscado rutas alternativas, tuvo como consecuencia un retraso en la llegada de los camiones de la compañía «Eugen Schimdberger, Internationale Transporte und Planzüge», que entendía conculcada de forma no justificada la libre circulación de mercancías, y pidió la responsabilidad del Estado austríaco para que le indemnizara por los daños derivados de la inactividad de sus camiones, el lucro cesante y otros daños accesorios.

Tras una primera desestimación de la demanda en primera instancia, el tribunal de apelación planteó una cuestión prejudicial ante el Tribunal de Justicia, preguntando fundamentalmente si era obligación de un Estado miembro garantizar el libre acceso a las principales vías de tránsito y si dicha obligación prevalece sobre los derechos fundamentales, tales como la libertad de expresión y la

Asociación Española de Derecho del Trabajo y de la Seguridad Social, Logroño, http://www.aedtss.com/TERCERA PONENCIA MRPR.doc; SARRIÓN ESTEVE, J. (2010). «Social rights protection problems in conflicting situations with market freedoms in European Union Law», Revista Universitaria Europea, n.13, pp. 88 y ss.

25 Sentencia de 11 de diciembre de 2007, International Transport Worker's Federation y Finnish Seamen's Union c. Viking Line, asunto C-438/05.

26 Sentencia de 15 de julio de 2010, Comision c. Alemania, C-271/08.

27 Razones de espacio nos obligan a no abarcar su estudio. Vid. asunto C-265/95, Comisión c. Francia.

28 Sentencia de 3 de abril de 2008, Dirk Rüffert c. Land Niedersachsen, C-346/06.

29 Sentencia de 7 de octubre de 2010, Santos Palhota, asunto C-515/08. 
libertad de reunión; en caso afirmativo, se planteaba si la infracción del Derecho comunitario estaría suficientemente caracterizada para generar responsabilidad del Estado.

En sus Conclusiones, el Abogado General JACOBS ${ }^{30}$ distinguió el asunto planteado del caso Comisión c. Francia ${ }^{31}$ puesto que si bien en principio la inactividad de las autoridades austríacas permitiendo el obstáculo a la libre circulación de mercancías por acciones privadas sería una vulneración del art. 28, esta vulneración estaría justificada por la tutela, por parte de las autoridades, del derecho fundamental de asamblea y de expresión derivado de la Constitución austríaca; además las restricciones a la libre circulación de mercancías producidas como consecuencia de la inactividad de las autoridades eran proporcionales teniendo en cuenta la ponderación que habrían realizado para evitar excesivos daños, contrastando esto con lo que había ocurrido en el asunto Comisión c. Francia. ${ }^{32}$ Así, planteaba que se debían considerar los derechos fundamentales como un interés legítimo que sería encuadrable dentro del interés público previsto de forma expresa en el Tratado y que serviría para justificar la restricción a la libertad económica. ${ }^{33}$ Por otro lado, constataba que existía una problema derivado de las divergencias entre los catálogos de derechos fundamentales de los Estados miembros puesto que no son trasladables de forma automática al ámbito comunitario. $^{34}$

La sentencia de 13 de junio de 2003 consideró, en primer lugar, que el cierre durante treinta horas de la autopista constituía una medida de efecto equivalente a las restricciones cuantitativas de la libre circulación de mercancías; y posteriormente valoró si dicha restricción estaba o no justificaba. ${ }^{35}$ Las autoridades austríacas habían permitido la concentración para garantizar los derechos fundamentales, y en particular los derechos de de libertad de expresión y de libertad de reunión, reconocidos y garantizados tanto por el CEDH como por la Constitución austríaca. ${ }^{36}$ Reafirma su jurisprudencia sobre los derechos fundamentales, que constituyen principios generales del Derecho comunitario, cuyo respeto

${ }^{30}$ Conclusiones del Abogado General F.G. JACOBS presentadas el 11 de julio de 2002, asunto $\mathrm{C}-112 / 00$.

31 Vid. Asunto C-265/95, Comisión c. Francia.

32 De hecho, llegaba a considerar que no haber concedido la autorización o bien condicionarla para reducir los efectos hubiera supuesto una restricción a los derechos fundamentales. Vid. apartado 110 de las Conclusiones.

33 Apartado 96.

34 Apartado 98.

35 Apartado 64.

36 Apartado 69.

(C) UNED. Revista de Derecho Político 
garantiza el propio Tribunal, para lo que se inspira en las tradiciones constitucionales comunes de los Estados miembros y en los instrumentos internacionales sobre protección de derechos humanos, a los que se han adherido los Estados miembros, en especial el CEDH $;{ }^{37}$ por lo que no se pueden admitir medidas incompatibles con el respeto de los derechos humanos en línea con Elliniki ${ }^{38}$.

Esto le llevaba a la necesidad de ponderar y conciliar las exigencias de protección de los derechos fundamentales con las exigencias derivadas de la libertad económica fundamental, en este caso la libre circulación de bienes o mercancías. ${ }^{39}$ Sin embargo, respecto a dicha ponderación parece que el TJCE realice una doble aproximación:

1) Desde el punto de vista de las libertades económicas fundamentales, pues si bien «la libre circulación de mercancías (...) en determinadas circunstancias puede ser objeto de restricciones por las razones enumeradas en el artículo 36 del mismo Tratado o en concepto de exigencias imperativas de interés gene$\operatorname{ral}(\ldots) »{ }^{40}$

2) Desde el punto de vista de los derechos fundamentales pues «si bien los derechos fundamentales controvertidos en el asunto principal están expresamente reconocidos por el CEDH y constituyen fundamentos esenciales de una sociedad democrática, del propio texto del apartado 2 de los artículos 10 y 11 de dicho Convenio resulta sin embargo que las libertades de expresión y de reunión pueden ser también objeto de determinadas limitaciones justificadas por objetivos de interés general, en la medida en que dichas excepciones estén previstas por la ley, respondan a una o más finalidades legítimas con arreglo a dichas disposiciones y sean necesarias en una sociedad democrática, es decir, justificadas por una necesidad social imperiosa y, en particular, proporcionales a la finalidad legítima perseguida».

37 Apartado 72.

38 Así, razona que «al imponerse el respeto de los derechos fundamentales tanto a la Comunidad como a sus Estados miembros, la protección de tales derechos constituye un interés legítimo que puede justificar, en principio, una restricción a las obligaciones impuestas por el Derecho comunitario, incluso en virtud de una libertad fundamental garantizada por el Tratado como la libre circulación de mercancías». Apartados 73 y 74 . El resaltado es mío.

39 Entiende que el asunto plantea «(...) la cuestión de la necesaria conciliación de las exigencias de protección de los derechos fundamentales en la Comunidad con las que se derivan de una libertad fundamental consagrada por el Tratado y, más concretamente, la cuestión del alcance respectivo de las libertades de expresión y de reunión, (...) y de la libre circulación de mercancías, cuando las primeras se invocan como justificación de una restricción de la segunda». Apartado 77. El resaltado es mío.

40 Apartado 78. 
De ahí deduce que los derechos a la libertad de expresión y a la libertad de reunión no constituyen derechos que no toleren restricciones (frente a otros derechos fundamentales como el derecho de toda persona a la vida, la prohibición de la tortura, la prohibición de la tortura y del trato inhumano o degradante) por lo que «deben considerarse según su función en la sociedad». Así, razona que pueden imponerse restricciones al ejercicio de esos derechos, en la medida en que éstas respondan efectivamente a objetivos de interés general y no constituyan, según el objetivo perseguido una intervención desmesurada e intolerable que afecte a la propia esencia de los derechos protegidos. ${ }^{41}$

Por tanto, estamos ante dos aproximaciones que conllevan la necesidad de ponderar los intereses en juego, atendiendo a las circunstancias concretas del caso, para verificar si se ha realizado un equilibro justo entre los intereses. ${ }^{42}$ El Tribunal de Justicia asume la competencia de realizar dicha ponderación, y si bien reconoce la facultad de apreciación que ostenta la autoridad nacional competente, no elude aplicar el test de proporcionalidad a la decisión tomada a nivel estatal para «verificar si las restricciones impuestas a los intercambios intracomunitarios son proporcionadas a la finalidad legítima perseguida, a saber, en el caso de autos, la protección de los derechos fundamentales». ${ }^{43}$

Para ello, en primer lugar rechaza la identidad del supuesto de hecho con el asunto resuelto en la sentencia Comisión c. Francia, que había invocado Schmidberger como precedente. ${ }^{44} \mathrm{Y}$ a continuación reconoce que las autoridades nacionales gozan de una amplia facultad de apreciación y acepta en esta ocasión que la decisión nacional era proporcional. ${ }^{45}$

Realmente se ha escrito mucho sobre esta sentencia, y podemos encontrar análisis contradictorios sobre la relación entre libertades económicas y derechos fundamentales que subyace en la misma:

a) Hay autores que entienden que en Schmidberger el Tribunal trata los derechos fundamentales como excepciones a las libertades económicas, es decir, asumiendo que existe una relación jerárquica a favor de las libertades. Sin embargo, a diferencia de la propuesta del Abogado General, los derechos fundamentales no se justificarían dentro de la cláusula de orden público, sino como exigencias im-

\footnotetext{
41 Apartado 80.

42 Apartado 81.

43 Apartado 82.

44 Vid. Apartados 85-88.

45 Vid. Apartados 89-93.
} 
perativas (mandatory requirements), lo que implicaría que el Tribunal seguiría la doctrina Cassis de Dijon. ${ }^{46}$

Sin embargo, ni siquiera es pacífica esta segunda cuestión, puesto que entre quienes defienden que el Tribunal asume la existencia de una relación jerárquica favorable a las libertades económicas, hay quien duda de que haya una justificación como mandatory requirements, razonando que no se puede descartar su consideración dentro de la cláusula de orden público; ${ }^{47}$ o quienes creen que de la sentencia se podría interpretar que los derechos fundamentales constituirían una especie de justificación «flotante» sujeta al test de proporcionalidad. ${ }^{48}$

b) Otro sector doctrinal entiende que el Tribunal de Justicia va más allá, y trata a libertades y derechos fundamentales como valores complementarios, sin relación jerárquica alguna resolviendo el conflicto a través de la ponderación. ${ }^{49}$

c) Incluso hay autores que entienden que sí hay relación jerárquica, pero ésta se produciría a favor de los derechos fundamentales, y el Tribunal de Justicia estaría atribuyendo la primacía a los mismos frente a las libertades económicas. ${ }^{50}$

Sin duda todas estas interpretaciones son defendibles, y es que no cabe duda que estamos ante una compleja sentencia.

Como hemos manifestado, en nuestra opinión cabe identificar en la sentencia dos discursos diferentes: uno de ellos está dedicado a las libertades económi-

46 HELISKOSKI, J. (2004). «Fundamental Rights versus Economic Freedoms in the European Union: Which paradigm?», en PETMAN, J., KLABBERS, H. (eds.) Nordic Cosmopolitanism: Essays in International Law for Martti Koskenniemi, Leiden, Martinus Nijhoff Publishing, p. 339; DÍAZ CREGO, M. (2009). Protección de los derechos fundamentales en la Unión Europea y en los Estados miembros, Madrid, Reus, pp.152-153; ROMÁN GONZÁLEZ, E. (2010). «Libertades económicas y derechos fundamentales. La doctrina de los Mandatory Requirements en la Jurisprudencia del TJCE», Boletín Mexicano de Derecho Comparado, nueva serie, n. 127, p. 538; KRZEMINSKAVAMVAKA, J. op. cit., pp. 7 y ss.; LINDFELDT, M. op. cit., p. 215; BARNARD, C. op. cit., p. 109; y de una forma crítica SCHUTTER, O. de. (2004). «The implementation of the EU Charter of Fundamental Rights through the Open Method of Coordination», Jean Monet Working Paper, n. 7, Jean Monnet Center for International and Regional Economic Law \& Justice, NYU School of Law. http://jeanmonnetprogram.org/papers/04/040701.htmln, p. 8.

47 PERIŠIN, T. op. cit., 88.

48 Ídem, pp. 89-90.

49 ROSAS, A. (2005). «Fundamental rights in the Luxemburg and Strasburg Courts», en BAUDENBACHER, C., TRESSELT, P., ÖRLYGSSON, T. (eds.). The EFTA Court: Ten Years on, Oxford, Hart Publishing, pp. 167-168; y TICHTY, L., «Fundamental rights and fundamental freedoms: short remarks», en PERNICE, I., ZEMÁNEK, J. (eds.) A Constitution for Europe: The $I G C$, the Ratification Process and Beyond, Nomos, www.ecln.net/elements/conferences/book_prag/TichyFinal.pdf, op. cit. p. 1.

50 GONZALES, G. op. cit., p. 223. 
cas y otro a los derechos fundamentales. ${ }^{51}$ Esto explica que existan apartados de la sentencia que dan a entender la existencia de una relación jerárquica entre libertades económicas y derechos fundamentales a favor de las primeras; mientras que otros apartados de la misma sentencia manifiestan un discurso diverso y favorable a los derechos fundamentales, en los que donde derechos y libertades constituyen valores complementarios, o incluso en alguno de ellos los derechos fundamentales, podría entenderse, gozarían de preferencia.

Ahora bien, dentro de las interpretaciones doctrinales que antes hemos expuestos, nos parece que existen dos más adecuadas a la vista de estos dos discursos Así, parece razonable poder entender que exista en la sentencia una concepción de la relación como jerárquica y favorable a las libertades económicas, donde los derechos fundamentales son excepciones. Se trataría de excepciones no previstas de forma expresa en el Tratado, ni tampoco de mandatory requirements, puesto que el TJCE no se refiere a los derechos fundamentales de forma explícita como tales; y por tanto entenderíamos que éstos estarían más próximos a constituir una justificación de carácter especial o flotante, que a mandatory requirements.

Sin embargo, también es perfectamente defendible que hay una ponderación y búsqueda de equilibrio, desde una concepción de relación de complementariedad e igualdad de estatus, y donde libertades económicas y derechos fundamentales se limitan mutuamente. Esta interpretación de la ponderación basada en la complementariedad ha sido desarrollada y defendida fundamentalmente por ROSAS y AVBELJ, y entiende que el Tribunal estaría tratando a las libertades económicas y los derechos fundamentales de una forma complementaria, de tal forma que no se establece una relación jerárquica sino complementario de las libertades y los derechos. Así, el hecho que el Tribunal comenzara el examen sobre la base de la violación de la libre circulación de mercancías estaría motivado por la forma de plantear la cuestión prejudicial, recordando que el Tribunal incide en que la mayoría de los de derechos fundamentales no son absolutos, como era el caso, por lo que la solución pasaba por la ponderación y la aplicación del test de proporcionalidad; entendiendo que en caso de que el conflicto se hubiera dado con un derecho fundamental de carácter absoluto, no habría aplicado el test de proporcionalidad. ${ }^{52}$

51 En realidad, podríamos decir que la sentencia fluctúa entre el discurso clásico sobre las libertades económicas como principios fundamentales que sólo admiten restricciones justificadas por otros valores (donde se incluirían también los derechos fundamentales); y un discurso de tutela de los derechos fundamentales donde son estos la regla general, y en determinados casos pueden verse limitados.

52 Apartados 81 y 82.

(C) UNED. Revista de Derecho Político 
De esta forma, los derechos fundamentales no constituirían excepciones a las libertades económicas fundamentales, sino que gozarían de la misma posición fundamental en el ordenamiento europeo, es más, si estuviéramos ante derechos de carácter absoluto, no habría ponderación posible, al tratarse de derechos susceptibles de limitación, entonces se produce la ponderación. ${ }^{53}$

En cualquier caso, la importancia que reviste la sentencia es clara, puesto que desplaza el punto de gravedad de las libertades económicas hacia los derechos fundamentales que asumen un papel de mayor protagonismo del que habían alcanzado hasta entonces en relación a las libertades económicas; ${ }^{54}$ lo que se une a una aplicación más flexible del test de proporcionalidad, ${ }^{55}$ o lo que se ha venido en llamar, incluso, la aplicación de otro tipo de test, un «balance exercise», que podría asemejarse más a un test de razonabilidad. ${ }^{56}$

b) La tutela de la dignidad humana: Omega (2004)

«Omega», una empresa situada en Bonn, llevaba a cabo la explotación de unas instalaciones dedicadas a juegos de láser o laser-sport, bajo el nombre de «laseródromo», y al observar que en el mismo se permitían juegos con objeto de disparar a blancos humanos mediante rayos láser («jugar a matar»), la autoridad gubernativa de Bonn le prohibió seguir con los mismos, basando dicha prohibición en la normativa alemana que permite la adopción de medidas para evitar amenazas a la seguridad o el orden público. La autoridad alemana argumentó que estos juegos suponían una banalización de la violencia, y vulneraban valores fundamentales del orden público. ${ }^{57}$

Una cuestión que quedaba clara en el análisis de la Abogado General, ${ }^{58}$ era que la dignidad humana gozaba un estatus especial en la Constitución alemana, puesto que gozaba de autonomía y de una garantía superior a la verificable en los tratados internacionales y en las constituciones de otros Estados miembros donde

53 Apartado 80.

54 LAZARI, A. (2009). «La nueva gramática del constitucionalismo judicial europeo», Revista de Derecho Comunitario Europeo, n. 33, pp. 511-512.

55 AVBELJ, M. (2004). «European Court of Justice and the Question of Value Choices», www.jeanmonnetprogram.org/papers/04/040601.pdf, pp. 72 y ss.; ALEMANNO, A. (2004). «A la recherche d'un juste équilibre entre libertés fondamentales et droits fondamentaux dans le cadre du marché intérieur», Revue du droit de l'Union européenne, n.4, p. 738; SCHUTTER, O. de. op. cit., p. 11; DÍAZ CREGO, M. op. cit., p. 153.

56 BIONDI, A.. op. cit., pp. 59-60.

57 Apartados 3-6.

58 Conclusiones de la Abogado General Christine STIX-HACKL presentadas el 18 de marzo de 2004, asunto C-36/02. 
gozaba de la categoría de un artículo general o un principio constitucional. ${ }^{59}$ Esto motiva que el razonamiento de STIX-HACKL se diferencie de la línea Schmidberger, pues «al Tribunal de Justicia le resulte difícil equiparar sin más el contenido de la garantía de la dignidad humana establecida en la Ley Fundamental alemana con el de la garantía de la dignidad humana reconocida en el Derecho comunitario» ${ }^{60}$. Esto, le lleva a recomendar «apreciar la medida nacional de que se trata a la luz del Derecho comunitario», y por tanto, interpretar el supuesto de justificación de orden público que invocan las autoridades alemanas, de acuerdo a la importancia de la dignidad humana en el ordenamiento comunitario, donde se ha reconocido como principio general de Derecho comunitario, deduciendo que el Tribunal podría no admitir interpretaciones de las libertades fundamentales que permitieran actividades que vulneraran la dignidad humana. ${ }^{61}$

En la sentencia del 14 de octubre de 2004, el Tribunal de Justicia razonó que estábamos ante una restricción de las libertades de circulación de mercancías y de prestación de servicios, pero consideró como principalmente afectada la libre prestación de servicios, al ser la libre circulación de mercancías secundaria y subordinada a la otra.

Teniendo en cuenta que la prohibición de la actividad económica se había invocado en base al orden público, el Tribunal tuvo que razonar que la excepción por orden publico no puede ser determinada de forma unilateral sin control por parte de las instituciones comunitarias; pero que las circunstancias que justifican el recurso al mismo pueden variar de un país a otro e incluso de una época a otra, teniendo que reconocer una margen de apreciación a las autoridades competentes $^{62}$. En este caso, la consideración por parte de las autoridades alemanas de que la actividad prohibida amenazaba el orden público se sustentaba en que la actividad prohibida menoscababa la dignidad humana en tanto que derecho consagrado en la Constitución alemana. ${ }^{63}$

El Tribunal, en línea con lo planteado por la Abogado General, reconoció que el respeto de la dignidad humana goza de un régimen de derecho fundamental autónomo en Alemania, pero entendió que esto era irrelevante a los efectos de considerar indudable que «el objetivo de proteger la dignidad humana es compatible con el derecho comunitario»; ${ }^{64} \mathrm{y}$ que el respeto de los derechos fundamentales que

\footnotetext{
59 Apartado 84 de las Conclusiones.

60 Apartado 92 de las Conclusiones.

61 Apartado 93 de las Conclusiones.

62 Apartados 30 y 31.

63 Apartado 32.

64 Apartado 34.
}

(C) UNED. Revista de Derecho Político 
se impone a la Comunidad y a los Estados miembros constituye un interés legítimo que puede justificar en principio una restricción a las obligaciones del derecho comunitario, recordando la jurisprudencia de Schmidberger. ${ }^{65}$

En este sentido, se descartaba el planteamiento de una posible diferenciación sustancial a la hora de considerar un derecho fundamental en función de si está reconocido solamente en la constitución de un Estado miembro o se corresponde con las tradiciones constitucionales comunes y por tanto forma parte del ámbito comunitario. ${ }^{66}$

A continuación respondía la cuestión prejudicial en el sentido de que el Derecho comunitario no se opone a que dicha actividad económica sea prohibida «por motivos de protección del orden público debido a que esta actividad menoscaba la dignidad humana» ${ }^{67}$.

A primera vista, y a diferencia de Schmidberger, aquí no se trataba de una falta de actuación de las autoridades del Estado miembro, sino de una acción positiva de las mismas. En este sentido, queda constatado que las autoridades de los Estados miembros pueden tomar acciones positivas, intervenir incluso de forma preventiva mediante una prohibición para proteger los derechos fundamentales. Estos derechos fundamentales no necesariamente tienen que corresponder con los derechos fundamentales de todos los Estados miembros; aunque sigue teniendo competencia el Tribunal de Justicia para examinar si la medida adoptada es adecuada para el fin previsto, siendo la tutela de la dignidad humana un fin legitimo que permite adoptar una prohibición para proteger el orden público.

La cuestión que cabe plantearse es qué relación guardan en esta sentencia libertades económicas y derechos fundamentales, si hay relación jerárquica o no, y en su caso a favor de quien.

Lo cierto es que la tutela de la dignidad humana se justifica dentro de la excepción de orden público prevista en el Tratado. Esto nos debería llevar a excluir la consideración de la tutela de los derechos fundamentales como exigencias imperativas. ${ }^{68}$ Naturalmente, tanto si se consideran los derechos fundamentales como excepciones expresas previstas en el Tratado, como mandatory requirements,

65 Apartado 35.

66 Apartados 39 y 40.

67 Apartado 41

68 HATZOPOUlOS, V., y UYENDO, T. (2006). «The Case Law of the ECJ Concerning the Free Provision of Services: 2300-2005», Common Market Law Review, v.43, n. 4, pp. 923-991. Esto ya se había planteado con ocasión de la sentencia Schmidberger, pero no nos parece justificado. Vid. OLIVER, P., y ROTH, W. H. (2004). «The Internal Market and the Four Freedoms», Common Market Law Review, v. 41, n. 1, p. 435. 
en ambos casos existe una relación jerárquica a favor de las libertades económicas, constituyendo los derechos fundamentales una excepción. ${ }^{69}$

En esta línea, la divergencia de Omega con Schmidberger se centraría solamente en que aquí no se justificarían como mandatory requirements, sino dentro de la excepción de orden público. Para KRZEMINSKA-VAMVAKA la razón estribaría en que el derecho fundamental tutelado en Omega no supera el ámbito nacional, no responde a las tradiciones constitucionales comunes de los Estados miembros. ${ }^{70}$

Sin embargo, en nuestra opinión este planteamiento no se podría deducir de forma nítida en la sentencia. Así, es innegable que el TJCE considera adecuada la medida prohibitiva basada en el orden público, pero esto es así precisamente porque fue la justificación alegada por las autoridades alemanas, que podrían haber recurrido a los mandatory requirements y no lo hicieron. En última instancia, la justificación de la medida es la protección de la dignidad humana en uno u otro caso. Es más, es la protección de la dignidad humana como principio general de derecho comunitario, relativizándose el hecho de que estuviera consagrada de forma autónoma en la Constitución alemana, puesto que debe ser respetada en el orden legal europeo en su conjunto. ${ }^{71}$ Por ello, entendemos que en caso de que se hubiera utilizado la protección de la dignidad humana como causa justificativa de la medida prohibitiva sin acogerse a la excepción del orden público, también hubiera sido admitida por el Tribunal de Justicia, todo y que la dignidad humana es un principio general de Derecho comunitario. Así, también en Omega, como ocurría en Schmidberger, encontramos una relación de complementariedad entre libertades y derechos fundamentales, con equivalencia de estatus y autolimitándose mutuamente.

c) La tutela del principio de igualdad: Sayn Wittgestein (2010)

Tras el fin de la Primera Guerra Mundial, la nueva República de Austria abolió la nobleza y los privilegios vinculados a la misma, como ocurrió también en Alemania, pero con una diferencia, pues en Austria la prohibición extendía también al uso de partículas de carácter nobiliario como «von» y «zu», a diferencia de lo que ocurría en Alemania. Una ciudadana austríaca que vivía en Alemania fue adoptada por un ciudadano alemán en dicha situación, y conforme al

69 Pero así parece asumirlo gran parte de la doctrina. Vid. LINDFELT, M., op. cit., p. 220; HELISKOSKI, J. op. cit., p. 440.

70 Así, estaríamos ante el surgimiento de una «complex theoretical framework for the protection of fundamental rights» que abriría dos líneas de solución divergentes. Vid. KRZEMINSKA-VAMVAKA, J. op. cit., pp. 18-22.

71 CARTABIA, M. op. cit., p. 10. 
Derecho alemán adquirió el apellido «Fürstin von Sayn-Wittgestein», pero mantuvo la nacionalidad austríaca, haciendo constar dicho apellido en el Registro Civil austríaco. Además se le renovó el pasaporte austriaco al menos una vez durante el 2001, y le fueron expedidos dos certificados de nacionales, y en todos los documentos constaban dicho nombre. Por otro lado esta ciudadana ha vivido y ejerciendo su actividad profesional esencialmente en Alemania, pero también fuera de dicho Estado interviniendo en la venta de castillos y casas solariegas.

El Tribunal Constitucional austríaco dictó una sentencia de 27 de noviembre de 2003 en la que resolvió una situación similar declarando que la Ley de abolición de la nobleza, que gozaba de rango constitucional, aplicaba en este ámbito el principio de igualdad, e impedía por lo tanto a un ciudadano austríaco adquirir un apellido que incluyera un antiguo título nobiliario, por medio de la adopción de un ciudadano alemán que lo ostenta legalmente; puesto que en virtud de dicha ley de abolición los austríacos no estarían autorizados a utilizar títulos nobiliarios, incluidos los que tengan origen extranjero, ni siquiera como elementos dentro del apellido.

A raíz de dicha sentencia, una resolución administrativa rectificó la inscripción del apellido de la interesada, eliminando los elementos nobiliarios, que fue recurrida alegando vulneración de la libre circulación de personas al tener que usar apellidos diferentes en diferentes Estados miembros, así como el derecho al respeto de la vida familiar garantizado por el art. 8 del CEDH. Y el Verwaltungsgerichtshof que conoció del recurso judicial planteó la cuestión prejudicial.

En la sentencia que resuelve el caso, el Tribunal de Justicia, siguiendo las Conclusiones de la Abogado General SHARPSTON ${ }^{72}$, comienza por observar que la situación de la demandante entra en el ámbito de aplicación del Derecho de la Unión, dado que si bien las normas que rigen el apellido de una persona y el uso de título nobiliario son competencia de los Estados miembros, deben respetar el Derecho de la Unión al ejercer dicha competencia. La demandante es nacional de un Estado miembro y como ciudadana de la Unión ejerce su derecho a la libre circulación y residencia en otro, pudiendo invocar dichas libertades reconocidas por el art. 21 TFUE; y como ejerce en Alemania una actividad profesional de prestación de servicios a destinatarios de uno o más Estados miembros, también puede invocar as libertades reconocidas en el art. 56 TFUE. ${ }^{73}$

El Tribunal parte del reconocimiento de que el apellido de una persona es un elemento constitutivo de su identidad, y vida privada, quedando protegido por

72 Conclusiones de la Abogado General Sra. Eleanor SHARPSTON presentadas el 14 de octubre de 2010, asunto C-208/09, Ilonka Sayn-Wittgenstein.

73 Apartados 37, 38, y 39 y 40. 
el art. 7 de la Carta de los derechos Fundamentales, y el art. 8 del CEDH, que si bien no lo menciona de forma expresa lo incluye conforme a la jurisprudencia el TEDH. ${ }^{74}$ No sólo afecta a este derecho fundamental, sino también al derecho de circular y residir libremente en el territorio de otro Estado miembro; ${ }^{75}$ y en este sentido constituiría una restricción dicha libertad. ${ }^{76}$ No obstante, considera que esta restricción de la libertad de circulación y residencia estaría justificada, al entender que la invocación del Gobierno austriaco en referencia a la historia constitucional austriaca y la Ley de Abolición de la nobleza como elemento de la identidad nacional, debe interpretarse como una invocación del orden público; ${ }^{77}$ que si bien debe interpretarse en sentido estricto, ${ }^{78}$ se debe reconocer a las autoridades nacionales un margen de apreciación dentro de los límites impuestos por el Tratado. ${ }^{79}$ Tiene en cuenta la alegación del gobierno austríaco de que la Ley de abolición de la nobleza constituye una aplicación del principio de igualdad, ${ }^{80}$ cuyo respeto como principio general del derecho es una de las finalidades del ordenamiento jurídico de la Unión, ${ }^{81}$ pues como ya había declarado en Omega, no es indispensable que la medida restrictiva se corresponda a una concepción compartida por el conjunto de los Estados miembros en relación a la protección del derecho fundamental o interés legítimo, ${ }^{82}$ pero esto no excluye la necesidad de proporcionalidad. ${ }^{83}$

Por tanto, controla la proporcionalidad y adecuación de la limitación. Teniendo en cuenta que conforme al art. 4 TFUE, apartado 2, la Unión respeta la identidad nacional de los Estados miembros, como la forma republicana, entiende que «no parece desproporcionado que un Estado miembro pretenda garantizar el objetivo de preservar el principio de igualdad prohibiendo la adquisición, posesión o uso por sus ciudadanos de títulos nobiliarios o elementos nobiliarios que pudieran hacer creer a la persona que los usa que ostenta tal ho-

74 Apartado 52. Se refiere a las SSTEDH Burghartz c. Suiza, de 22 de febrero de 1994, y Stjerna c. Finlandia, de 25 de noviembre de 1994.

75 Apartados 53 y 54.

76 Apartado 71.

77 Apartados 83 y 84 .

78 Para que un Estado miembro no pueda determinar unilateralmente su alcance sin control de las instituciones europeas, pudiendo invocarse sólo «en caso de que exista una amenaza real y suficientemente grave que afecte a un interés fundamental de la sociedad» recordando la sentencia Omega. Apartado 86.

79 Apartado 87

80 Apartado 88

81 Apartado 89

82 Apartado 91.

83 Apartado 91.

(C) UNED. Revista de Derecho Político 
nor nobiliario ${ }^{84}$ por lo que razona que no puede considerarse una medida que menoscaba de manera injustificada la libre circulación y la libre residencia de los ciudadanos de la Unión. ${ }^{85}$

$\mathrm{Y}$ concluye que las autoridades nacionales podrían negarse a reconocer en todos sus elementos el apellido de un nacional, tal y como fue terminado en otro Estado miembro, cuando dicho apellido incluye un título nobiliario no permitido en el primero, conforme a su Derecho constitucional «siempre que las medidas adoptadas por dichas autoridades en este contexto estén justificadas por motivos de orden público, es decir, que sean necesarias al objetivo legítimamente perseguido». ${ }^{86}$ En definitiva, deja la decisión sobre la apreciación, en última instancia, de la proporcionalidad y adecuación de la restricción al juez nacional. ${ }^{87}$

En línea con Omega refuerza el acento o énfasis constitucional, en la medida en que ya no son sólo los derechos fundamentales de un Estado miembro los que se ponderan con las libertades del mercado, sino también un principio constitucional que define la identidad constitucional de un Estado miembro. Cabría aplicar aquí las reflexiones realizadas en Omega sobre la relación entre libertades económicas y derechos fundamentales y si existe o no jerarquía entre ambas categorías, a las que nos remitimos. Aunque ciertamente estaríamos ante la segunda ocasión en la que el Tribunal de Justicia acepta un valor constitucional nacional como excepción de orden público, en este caso un principio constitucional vinculado a la identidad constitucional. En este sentido, cabría sostener que se refuerza la posición de quienes sostienen que habría una diferenciación entre derechos y principios constitucionales que responderían a las tradiciones constitucionales comunes de los Estados miembros, que se tutelarían como exigencias imperativas; y derechos y principios constitucionales que no responden a dichas tradiciones constitucionales comunes, pero existiendo en un Estado concreto, se tutelarían a través de la excepción de orden público. Entendemos, sin embargo, que la aceptación de la restricción a la libre circulación de personas como excepción de orden púbico se debe fundamentalmente a las alegaciones realizadas

84 Apartado 93.

85 Apartado 94.

86 Fallo de la sentencia.

87 Se echa en falta una mayor consideración por las circunstancias concretas del caso en particular, que podrían haber llevado al Tribunal a razonar que de forma general la limitación justificada en el Derecho constitucional austríaco, sería ajustada al Derecho de la Unión, pero que en este caso concreto los perjuicios derivados de la modificación de un apellido que se ha estado utilizado legalmente y de buena fe durante 15 años (y que constata el propio Tribunal de Justicia) deberían motivar que no se hiciera pechar a la interesada con los mismos, y por tanto que se le permitiera la utilización de su apellido y circular libremente con él en la UE. 
por el gobierno austríaco en ese sentido, más que a la diferenciación antes mencionada, como también consideramos respecto a Omega. ${ }^{88}$

\subsection{La tutela de los derechos sociales}

Tal y como hemos anticipado nos vamos a ocupar de estudiar en este apartado los conflictos en los que intervienen los derechos sociales-laborales.

a) La tutela de las acciones colectivas I: Viking (2007)

Una empresa finlandesa, "Viking Line», se ocupaba de llevar a cabo un trayecto naval entre Tallín (Estonia) y Helsinki (Finlandia) bajo bandera finlandesa. En un momento determinado pretende cambiar de pabellón para poder beneficiarse de unos costes laborales inferiores. El sindicato finlandés convocó una huelga, y consiguió aumentar el número de trabajadores pero no la renuncia al proyecto. Además, el sindicato pretendía conseguir que Viking aceptara que en caso de cambio de pabellón no se podría despedir a trabajadores y se seguiría aplicando el convenio colectivo y el derecho finlandés. Se inició un primer procedimiento judicial en Finlandia por parte de Viking para tratar de detener la huelga que finalizó en la conciliación previa desistiendo Viking de la acción judicial. No obstante, la propia Viking solicitó a la justicia británica la declaración de la huelga y las medidas sindicales como contrarias al Derecho comunitario porque entendía que esas pretensiones suponían convertir en inútil el cambio de bandera. ${ }^{89}$ En primera instancia se estimó la demanda de Viking, pero en vía de apelación, el órgano judicial encargado de resolver el caso, decidió plantear una cuestión prejudicial ante el Tribunal de Justicia.

El Tribunal de Justicia dictó sentencia el 11 de diciembre de 2007 siguiendo las líneas marcadas por el Abogado General MADURO. ${ }^{90}$ Es importante, en este sentido, resaltar que si bien considera las acciones colectivas como restricciones que están dentro del ámbito de aplicación de las normas de sobre la libre circulación; ${ }^{91}$ por otro lado reconoce el derecho a adoptar medidas de conflicto colectivo, incluido el derecho de huelga, como derecho fundamental que forman

88 En cualquier caso, tendremos que estar atentos a la futura jurisprudencia sobre conflictos entre libertades de mercado y derechos fundamentales, que dará y quitará la razón al respecto.

89 Vid. Conclusiones del Abogado General Miguel POIARES MADURO presentadas el 23 de mayo de 2007, asunto C-348/05, apartados 2-12.

90 Vid. supra.

91 Apartados 32-37 de la sentencia. 
parte de los principios generales del Derecho comunitario cuyo respeto garantiza el Tribunal, lo que no excluye que puedan ser susceptibles de restricción. ${ }^{92}$

Esto no implica una exclusión del ámbito de aplicación de las disposiciones del Tratado, sino que exige una ponderación entre los derechos y las libertades fundamentales. ${ }^{93}$ En definitiva, siguiendo la línea marcada en Schmidberger y Omega, el Tribunal opta de forma clara por ponderar y resolver el conflicto teniendo en cuenta los intereses en juego, pero en esta ocasión dejando la decisión al juez nacional.

La relevancia del conflicto era nítida al tratarse del primer caso de conflicto entre un derecho social fundamental y una libertad económica. De las aproximaciones posibles al conflicto, si bien habíamos razonado que podían ser varias en función del estatus que se reconociera a derechos y libertades económicas fundamentales, entendemos que en esta ocasión la aproximación es mucho más nítida, optando el Tribunal opta por una equiparación de estatus entre derechos sociales fundamentales y libertades económicas, lo que conlleva a una ponderación entre valores equivalentes susceptibles de restricción mutua. Y esto a pesar de las críticas vertidas contra la sentencia por una supuesta «subordinación» del derecho de huelga frente a la libertad de establecimiento. ${ }^{94} \mathrm{~A}$ la vista de la sentencia Viking, no podemos afirmar que se haya subordinado de forma definitiva el derecho social de huelga frente a la libertad de establecimiento, sino que el Tribunal resuelve el conflicto a través del principio de proporcionalidad, como se evidencia en los apartados 40 y 45, y fundamentalmente el 79, donde resalta las dos dimensiones que viven en el ámbito comunitario. ${ }^{95}$

Sin embargo, el Tribunal de Justicia no termina de aplicar el test de proporcionalidad y deja en manos del juez nacional decidir si las medidas de conflicto colectivo adoptadas en el caso concreto eran adecuadas y proporcionadas para el fin perseguido.

Alguna doctrina vio con buenos ojos el reconocimiento de los derechos sociales como derechos fundamentales y por tanto, principios generales de Derecho

92 Apartados 43 y 44 de la sentencia.

93 Apartado 45 de la sentencia.

94 BAYLOS, A. (2007). «El derecho de huelga en Europa puesto en cuestión: la sentencia del Tribunal de Justicia sobre el caso VIKING», www.ccoo.es/comunes/temp/recursos/99999/115076.pdf; RODRIGUEZ-PIÑERO ROYO, M. op. cit., p. 96.

95 «Por tanto, dado que la Comunidad no sólo tiene una finalidad económica, sino también social, deben sopesarse los derechos derivados de las disposiciones del Tratado relativas a la libre circulación de mercancías, personas, servicios y capitales en relación con los objetivos perseguidos por la política social (...)» Apartado 79. 
comunitario, con independencia de su visión global de la sentencia. ${ }^{96}$ Pero no dejó de constatar que este reconocimiento era premisa necesaria para sujetar la acción sindical a las reglas del ordenamiento comunitario; ${ }^{97}$ y así se impusieron las libertades económicas fundamentales sobre los derechos sociales. ${ }^{98}$ De todas formas no parece que se haya dado la debida relevancia a otorgar el carácter de fundamental a los derechos sociales laborales, puesto que en algunos Estados miembros carecen si quiera de un reconocimiento similar, por lo que a partir de ahora los sindicatos podrían esgrimir su derecho a la acción colectiva frente a los Estados. ${ }^{99}$

b) La tutela de las acciones colectivas II: Laval (2007)

Estamos ante el segundo enfrentamiento entre las libertades económicas y los derechos sociales fundamentales que tiene que resolver el Tribunal de Justicia. Con la diferencia de que ya se había dictado la sentencia Viking y por tanto los derechos sociales ya se habían reconocido como derechos fundamentales tutelables en el ámbito comunitario como principios generales de Derecho comunitario. Sin embargo, como veremos, la resolución no es exactamente igual que en la sentencia Viking, a pesar del precedente que había sentado dicha sentencia.

«Laval» era una sociedad letona que desplazaba trabajadores letones a Vaxholm, Suecia, para la construcción de un centro escolar. La empresa tenía firmados convenios colectivos con el sindicato letón, pero ninguno con los sindicatos suecos, y tras iniciar negociaciones, estas no llegaron a buen puerto. El sindicato sueco de la construcción adoptó medidas de conflicto colectivo consistentes en el bloqueo de las obras, impidiendo la entrega de mercancías y piquetes que impedían la entrada a las obras de los trabajadores letones. Además se unió la acción

96 DAVIES, P. (2008). «One Step Foward, Two Steps Back? The Viking and Laval Cases in the ECJ», Industrial Law Journal, n. 2, pp. 26 y ss.; en el mismo sentido CORTI, M. (2008). «Le decisión ITF e LAVAL della Corte di Giustizia: un passo avanti e due indietro por l'Europa Sociale», Rivista Italiana di Diritto del Lavoro, n. 1, p. 249; RODRIGUEZ-PIÑERO ROYO, M op. cit., p. 96.

97 ORLANDINI, G. (2008). «Viking, Laval e Rüffert: i riflexxi sull diritto di sciopero e sull'auotnomia collettiva nell'ordinamento italiano",www.etui.org/en/Headline-issues/Viking-LavalRueffert-Luxembourg/2-Articles-in-academic-literature-on-the-judgements/Orlandini-G.-VikingLaval-e-Rueffert-i-riflessi-sul-diritto-di-sciopero-e-sull-autonomia-collettiva-nell-ordinamento-itali ano, p. 1.

98 RODRIGUEZ-PIÑERO ROYO, M. op. cit. p. 96.

99 En este sentido, ZAHN, R. (2008). «The Viking and Laval Cases in the Context of European Enlargement», Web Journal of Current Legal Issues, n.3, http://webjcli.ncl.ac.uk/2008/issue3/zahn3.html, p. 11. Esta autora pone de relieve que en Estados como el Reino Unido, por ejemplo, el derecho a la acción colectiva carece de reconocimiento legal. 
de solidaridad de otras organizaciones sindicales. La empresa Laval presentó una demanda solicitando la declaración de ilegalidad del bloqueo y de la acción solidaria, así como una indemnización por los daños sufridos; solicitando además como medidas cautelares el fin de estas medidas colectivas. El órgano jurisdiccional que conoció de la demanda optó por no estimar la solicitud de medidas cautelares, y ante las dudas que se le suscitaban en torno a la compatibilidad de las medidas de conflicto colectivo con el Derecho comunitario, decidió plantear una cuestión prejudicial. ${ }^{100}$

En sentencia de 18 de diciembre de 2007, el Tribunal de Justicia, apartándose del planteamiento del Abogado General MENGOZZI (que había propuesto una solución en línea con Viking) ${ }^{101}$ y tras examinar la compatibilidad con el Derecho comunitario de las acciones colectivas llevadas a cabo, si bien tiene en consideración que el ejercicio de la acción colectiva constituye un derecho fundamental tutelable como principio general de Derecho comunitario, deja claro que en este caso las medidas de conflicto colectivo adoptadas no estarían justificadas. ${ }^{102}$

Se trata de una sentencia muy criticada desde la doctrina laboralista argumentando que supone una restricción de los derechos sociales de los trabajadores, y una intromisión en las políticas sociales muy vinculadas a la sensibilidad de los Estados miembros. ${ }^{103}$ También ha recibido críticas desde los sindicatos europe-

100 En concreto planteaba dos preguntas: 1) Si era compatible con las disposiciones del TCE relativas a la libre prestación de servicios y a la prohibición de discriminación por razón de nacionalidad, así como con la Directiva 96/71, que los sindicatos trataran de obligar a un prestador de servicios extranjero, mediante medidas de conflicto colectivo a que se adhiera en un Estado de acogida a un convenio colectivo relativo a condiciones de trabajo y empleo como era el de la construcción, cuando el Estado de acogida carece de disposiciones expresas sobre la aplicación de condiciones de trabajo y empleo previstas en un convenio colectivo; y 2) si la prohibición de la legislación del Estado de acogida de la adopción de medidas sindicales de conflicto colectivo con el fin de dejar sin efecto un convenio colectivo celebrado por otras partes, al no ser aplicable a medidas de conflicto colectivo dirigidas contra empresas extranjeras que operan en Suecia y que desplazan a sus trabajadores, es contraria al Derecho comunitario constituyendo una prevalencia y primacía sobre los convenios colectivos extranjeros existentes.

Apartados 39 y 40 de la sentencia.

101 Conclusiones del Abogado General Paolo MENGOZZI presentadas el 23 de mayo de 2007, asunto Laval un Partneri Ltd v. Svenska Byggnadsarbetareförbundet y otros, C-341/05.

MENGOZZI proponía el reconocimiento de la posibilidad de entablar acciones de conflicto colectivo, y dejar la decisión sobre su adecuación al juez nacional en línea con lo resuelto por el TJCE en la sentencia Viking.

102 Vid. apartados 101,110 y 111.

103 DURÁN LÓPEZ, F. (2008). «Libre prestación de servicios y condiciones de trabajo», www.ccoo.es/comunes/temp/recursos/99999/115077.pdf 
os y aquellos que ven en la jurisprudencia del Tribunal un «excesivo peso de lo económico en el proceso de de integración europea» denunciando la legalización del dumping social en la Unión Europea. ${ }^{104}$ Aunque desde otras posiciones se reconoce como algo positivo el reconocimiento del derecho a la acción colectiva cuyo objetivo es evitar el dumping social como derecho fundamental dentro de los principios generales del Derecho comunitario, aunque en el caso concreto no se entendiera justificada la medida colectiva adoptada. ${ }^{105}$

Ciertamente, en este caso la aproximación que realiza el Tribunal de Justicia al conflicto sí parece decantarse por la prevalencia de las libertades económicas y en concreto respecto a la libre prestación de servicios frente al derecho de adopción de acciones colectivas. Esta sentencia plantea dudas sobre la equivalencia en el estatus de derechos y libertades económicas fundamentales. No encontramos una suficiente sustentación de la resolución de la ponderación por parte del Tribunal, el derecho fundamental a la acción colectiva no sólo es un derecho fundamental reconocido en diversos instrumentos internacionales, y un principio general del Derecho comunitario, sino que también está reconocido como tal en la Constitución sueca, y esto debería haber motivado que el Tribunal optara por dar indicaciones pero dejara cierto margen de apreciación al juez nacional, en línea con lo que había hecho en la sentencia Viking, y tal y como proponía MENGOZZI en sus Conclusiones Generales.

c) La tutela de la negociación colectiva: Comisión c. Alemania (2010)

Este caso tiene algunas peculiaridades puesto que es el único conflicto directo estudiado que no llega a conocimiento del Tribunal de Justicia a través de una cuestión prejudicial, sino a través de un recurso por incumplimiento de la Comisión Europea.

En Alemania, dentro del marco de los esfuerzos para desarrollar un sistema de planes de pensiones de empleo capitalizado, se aprueba la $\operatorname{Betr} A V G$, que regula la conversión de retribuciones salariales en aportaciones a planes de pensiones a instancia del trabajador. En base a dicha norma, la Confederación de organizaciones empresariales municipales y de servicios pactaron un convenio colectivo el 18 de febrero de 2003 (TV-EUmw/VKA), que reconocía a los trabajadores de los servicios públicos municipales el derecho a la conversión de su

104 QUADRA-SALCEDO JANINI, T. de la (2008). «TJCE - Sentencia de 18.12.2007, LA$V A L$, C-341/05- libre prestación de servicios-desplazamiento de trabajadores-la supuesta legalización del dumping social en el interior de la Unión Europea», Revista de Derecho Comunitario europeo, n. 31, p. 836.

105 Ídem, pp. 836 y 839. 
retribución. En el art. 6 del mismo se designaba expresamente las entidades y empresas aseguradoras a las que se encomienda en exclusiva la ejecución de la conversión salarial establecida. ${ }^{106}$

Esta previsión, a ojos de la Comisión Europea se saltaba el procedimiento de adjudicación de contratos públicos previsto en la Directiva 92/50, y vulneraba los principios de libertad de establecimiento y libre prestación de servicios (arts. 43 y 49 TCE) en la medida en que las administraciones locales y empresas municipales no llevaban a cabo una licitación a escala europea de la adjudicación de la gestión de los planes de pensiones. En cambio, el gobierno alemán entendía que las entidades municipales no podían ser consideradas como entidades adjudicatarias a los efectos de la normativa sobre contratación pública, teniendo en cuenta los compromisos derivados del convenio colectivo; y además los contratos entre dichos entes con las empresas gestoras de los planes de pensiones no serían contratos públicos, sino contratos individuales de trabajo, estando tutelados por la autonomía negocial del convenio colectivo. ${ }^{107}$ Dado que no se solucionó la diferencia de posturas, la Comisión remitió finalmente un cuestionario sobre la justificación de la exclusión de la aplicación de las directivas, al entender no justificada la respuesta alemana interpuso recurso. ${ }^{108}$

La Abogado General TRSTENJACK planteaba en sus Conclusiones ${ }^{109}$ que lo que se suscita es «la existencia y las consecuencias de un conflicto entre las obligaciones derivadas de las libertades fundamentales, por un lado, y el derecho de negociación colectiva y el derecho de autonomía negocial, por otro», ${ }^{110}$ teniendo en cuenta que estos derechos son principios generales del Derecho co-

106 En concreto preveía que la gestión del régimen de pensiones se atribuyera, en principio, a entidades públicas de previsión complementaria, si bien los empresarios municipales podían decatnarse por una colaboración la Sparkassen Finanzgruppe o con aseguradoras municipales; permitiéndose también la celebración de convenios colectivos a escala regional que establecieran excepciones (apartado 21 de las Conclusiones de la Abogado General).

107 Adjuntaron también un dictamen jurídico redactado por el Profesor Koening y el Sr. Pfromm que añadía a dichas consideraciones que los umbrales establecidos en las Directivas no se habían alcanzado en cada caso por separado. Vid. Apartado 26 de las Conclusiones de la Abogado General.

108 La Directiva anterior fue sustituida por la Directiva 2004/18 que entró en vigor el 1 de febrero de 2006. La Comisión insistió en el incumplimiento de la normativa sobre adjudicación de contratos públicos (según la anterior Directiva hasta el 31 de enero de 2006, y después según la nueva) y emprendió una acción de incumplimiento contra el gobierno alemán, que mantuvo su postura.

109 Conclusiones de la Abogado General Verica TRSTENJACK presentadas el 14 de abril de 2010.

110 Apartado 3. 
munitario y por tanto «derechos sociales fundamentales» y tienen que compatibilizarse con las directivas sobre contratación pública, que concretizan la libertad de establecimiento y la libre prestación de servicios. ${ }^{111} \mathrm{Y}$ tras realizar un interesante estudio de las relaciones entre libertades y derechos fundamentales, excluyendo la existencia de una relación jerárquica en la medida en que tanto libertades como derechos supondrían restricciones recíprocas; ${ }^{112}$ considera que si bien los entes locales debían atenerse al Derecho comunitario, se debe desestimar el recurso porque la Comisión se basó en presunciones no probadas. ${ }^{113}$

Por su parte, en la sentencia de 15 de julio de 2010 el Tribunal de Justicia considera que el art. 6 del Convenio colectivo, con independencia de su finalidad social, tiene como consecuencia «excluir por completo y por tiempo indefinido la aplicación de las normas contenidas en las Directivas 92/50 y 2004/18 en el ámbito de los plantes de pensiones de los trabajadores municipales». ${ }^{114}$ Analiza las alegaciones del gobierno alemán: la de que este artículo permite la implicación de los trabajadores y obtener para sus intereses unas condiciones más favorables que mediante un procedimiento de adjudicación para cada empresa municipal, rechazándola porque sería posible la conciliación de dichos intereses con los procedimientos de adjudicación de contratos públicos, que pueden imponer a los licitadores condiciones acordes a dichos intereses; ${ }^{115}$ que las ofertadas de las entidades y empresas que contempla el art. 6 se basan en el principio de solidaridad, no realizando ninguna selección de candidatos por criterios médicos, y la rechaza considerando que se pueden mantener estos elementos de solidaridad con la aplicación del procedimiento de adjudicación de contratos, pudiendo exigir dicho procedimiento el espeto a dichas condiciones solidarias para evitar una selección por criterios médicos; ${ }^{116}$ la experiencia y solidez financiera de las entidades y empresas mencionadas en el art. 6 y que su selección hace atractiva la conversión salarial para los trabajadores de la función pública municipal, pero como indica el Tribunal las directivas permiten la comprobación por parte de las entidades adjudicatarias de la capacidad profesional y financiera de los licitadores, y por otro lado, no cabe suponer que como regla general les falte a los que no constan en el art. 6, además de que las empresas privadas que ofrecen seguros de

111 Apartados 3 y 4, vid supra.

112 Apartados 184 y ss.

113 Apartados 235-237.

114 Apartado 53.

115 Apartados 54-56.

116 Apartados 57 y 58.

(C) UNED. Revista de Derecho Político 
grupo así como los fondos de pensiones de empleo están sujetos a normas de supervisión prudencial para garantizar su solidez financiera. ${ }^{117}$

El Tribunal constata, además, que algunas empresas municipales han utilizado el art. 6 para adjudicar directamente contratos de seguros a empresas diferentes a las mencionadas el dicho artículo, sin que esto aparentemente haya mermado el interés social; ${ }^{118}$ que permite que los empresarios municipales eviten tener que recurrir a un procedimiento individual de selección de entidad, y los precios exigidos por las entidades contempladas son módicos, pero éstas consideraciones no pueden justificar la exclusión de los procedimientos de adjudicación. ${ }^{119}$

Tras el rechazo de las alegaciones efectuadas por el Gobierno alemán, el Tribunal de Justicia razona que «el cumplimiento de las Directivas en materia de contratos públicos de servicios no resulta incompatible con la consecución del objetivo social perseguido por las partes (...) al ejercer su derecho a la negociación colectiva» ${ }^{120}$; y concluye que la República Federal de Alemania había incumplido las obligaciones derivadas de las directivas. ${ }^{121}$

Como se puede observar, estamos ante un nuevo conflicto entre los derechos sociales y las libertades económicas fundamentales, en el que el Tribunal de Justicia vuelve a ponderar entre ambas categorías en juego, en línea con las sentencias Viking y Laval. Se ha vuelto a insistir en que en la resolución del conflicto prevalecerían las libertades económicas frente a los derechos sociales fundamentales en línea con las sentencias Viking y Laval, en lo que se ha convertido en una constante crítica sindical. ${ }^{122}$

En su momento, razonamos que no era así en la resolución del caso Viking, aunque sí de forma más clara en Laval, y que era mejor la solución Viking. De todas formas, hay que apuntar la singularidad de que el Tribunal de Justicia tenga conocimiento del caso de conflicto a través de un recurso interpuesto por la Comisión y no a través del planteamiento de una cuestión prejudicial. Esto es importante porque la solución Viking no cabe en un caso como el resuelto aquí, pues al tratarse de un recurso de incumplimiento el Tribunal de Justicia tiene que emitir una decisión sobre las medidas estatales, y decidir si condena o no al Estado, como hace aquí.

117 Apartados 59-62.

118 Apartado 63.

119 Apartados 64 y 65.

120 Apartado 66.

121 Apartado 105 de la Sentencia.

122 Vid. Declaraciones del Secretario General de Confederazión Europea de Sindicatos (CES), accesibles en www.etuc.org/a/7521. 


\section{CONCLUSIONES}

Los derechos fundamentales han adquirido una gran importancia en el ámbito del Derecho comunitario, hoy Derecho de la UE, e intervienen en situaciones de conflicto con las libertades económicas. Hemos tratado de identificar y delimitar estos casos para poder estudiar la solución adoptada por el Tribunal en cada uno de ellos, y tratar de extraer una doctrina general en relación a la resolución de los mismos.

Y sin perjuicio de que hemos realizado algunas reflexiones y aportado nuestro punto de vista a lo largo del trabajo, parece conveniente plasmar de forma breve aquello que consideramos más relevante a modo de conclusiones:

Del estudio llevado a cabo podemos concluir que el Tribunal de Justicia no ha asumido de forma nítida una posición sobre la relación jerárquica entre libertades y derechos fundamentales, y consecuentemente no ha construido una doctrina general clara y precisa que pueda servir para la resolución del conflicto, sino que la resolución ha dependido del caso concreto ante el que se ha encontrado.

No obstante, entendemos que la aproximación que más se ajusta a su jurisprudencia sobre la relación entre libertades económicas y derechos fundamentales es la que considera que ambas categorías son equivalentes, y gozan de un estatus equiparable.

Aún así, dentro de los conflictos estudiados se pueden apreciar dos grupos diferenciados en función del tipo de derecho o principio que interviene, así como por la diferente sensibilidad que parece mostrar el Tribunal hacia unos y otros.

En este sentido, podemos hablar de un primer grupo que hemos englobado dentro del apartado «énfasis constitucional», en el que encontramos conflictos con libertades económicas en los que intervienen derechos fundamentales de carácter civil o político (Schmidberger), la dignidad humana (Omega) o incluso el principio constitucional de igualdad (Sayn Wittgestein); y un segundo grupo formado por aquellos conflictos con las libertades económicas en los que se ven afectados derechos de naturaleza social-laboral, y dentro de los mismos el derecho a la acción colectiva (Viking, y Lava), y el derecho a la negociación colectiva (Comisión c. Alemania).

En los conflictos del primer grupo cabe destacar cómo son resueltos por el Tribunal de Justicia a través de la ponderación y utilizando el principio de proporcionalidad. En Schmidberger y Omega, el derecho a la libertad de expresión y de reunión, y la dignidad humana prevalecen frente a la libre circulación de mercancías y la libre prestación de servicios, respectivamente; en Sayn Wittgestein, es el principio constitucional de igualdad el que prevalece. 
Los derechos sociales-labores han sido reconocidos en la jurisprudencia del Tribunal de Justicia como derechos fundamentales tutelables como principios generales de Derecho comunitario desde Viking, y así ha sido confirmado en Laval y en Comisión c. Alemania. Por tanto, estos derechos sociales-laborales constituyen también derechos fundamentales y al entrar en conflicto con libertades económicas fundamentales, son resueltos también aplicando el principio de proporcionalidad. Sin embargo, aparentemente de forma menos favorable hacia los derechos.

En Viking, el Tribunal de Justicia pondera entre el derecho a la acción colectiva y la libre prestación de servicios, pero no termina de aplicar el test de proporcionalidad, dejando la decisión al juez nacional. Si termina el test en Laval, pero lo hace considerando que la medida restrictiva de la libre prestación de servicios fundamentada en la acción colectiva era contraria al Tratado. Entendemos que sería más preferible la solución Viking. En otras palabras, en caso de que la ponderación no llevara a hacer prevalecer el derecho fundamental en juego frente a la libertad económica, entendemos que el Tribunal debería dar el mayor margen de apreciación posible al juez nacional para garantizar el mayor nivel de protección posible al derecho fundamental afectado.

En Comisión c. Alemania, el Tribunal resuelve un conflicto entre la libre prestación de servicios y el derecho a la negociación colectiva, condenando a Alemania al no considerar justificada la restricción a la libertad económica que se había introducido en un convenio colectivo y que suponía obviar la legislación europea sobre contratos públicos. Como hemos comentado, aquí no es adecuada la solución Viking al tener conocimiento del asunto a través de un recurso por incumplimiento.

Para resumir podríamos decir que en el ámbito del Derecho de la Unión Europea se producen una serie de conflictos entre libertades económicas y derechos fundamentales que el Tribunal de Justicia resuelve a través del principio de proporcionalidad atendiendo a las circunstancias de cada caso, por lo que es difícil extraer una doctrina general. No obstante, parece razonable entender que trata a libertades económicas y derechos fundamentales como categorías que ostentan el mismos estatus en el Derecho de la Unión.

\section{Title}

Conflicts between economic freedoms and fundamental rights in european court of justice case law

\section{Sumary}

1. INTRODUCTION. 2. DELIMITATION AND STUDY OF CONFLICTING CASES. 2.1. Indirect conflicts. 2.2. Direct con- 
flicts. 2.2.1. The constitutional emphasis. 2.2.2. Social rights protection. 3. CONCLUSIONS.

\title{
Resumen
}

Como es sabido, la protección de los derechos fundamentales ha cambiado mucho en la Unión Europea. En un primer momento, los Tratados constitutivos de las Comunidades Europeas guardaban silencio sobre la protección de los derechos humanos, y fue el Tribunal de Justicia el que la hizo posible. A diferencia de los derechos fundamentales, las libertades económicas han gozado siempre de una relevancia explícita en los Tratados como instrumentos al servicio de la realización del mercado y de la integración económica.

Sin embargo, los derechos fundamentales han ganado importancia con los años, tanto en la jurisprudencia del Tribunal de Justica como en el Derecho de la Unión Europea. Y finalmente han comenzado a colisionar con las libertades económicas.

Realmente, existen dos tipos de relación entre libertades económicas y derechos fundamentales: una positiva en la que los derechos fundamentales sirven para proteger a las libertades económicas; y una negativa con situaciones de conflicto entre libertades económicas y derechos fundamentales que debe ponderar el Tribunal de Justicia.

En el primer tipo de relación, los casos más representativos comienzan con Elliniki (1991) y continúan con Carpenter (2002) y Karner (2004). En estas sentencias, el Tribunal de Justicia establece que los Estados miembros deben respetar los derechos fundamentales no sólo cuando aplican el Derecho comunitario, sino también cuando pretenden establecer una excepción a las obligaciones derivadas del Tratado. En este sentido, una medida restrictiva de una libertad económica no solamente debe estar justificada, sino que también debe respetar los derechos fundamentales como principios generales del Derecho comunitario.

En cualquier caso, una relación de sinergia positiva no plantea problemas para la protección de los derechos fundamentales. Es en los casos de conflicto como Schmidberger (2003), Omega (2004), Viking (2007), o Laval (2007), donde podemos encontrar los problemas. De hecho, la cuestión es ¿cómo resuelve el Tribunal de Justicia un conflicto entre libertades económicas y derechos fundamentales?

\begin{abstract}
As it is known, fundamental rights protection has changed a lot in European Union. At first, the Treaties constituting European Communities were silent on human rights protection, and ECJ had to make it
\end{abstract}


possible. Unlike fundamental rights, market freedoms have always enjoyed an explicit relevance in the Treaties as instruments to serve the attainment of market and economic integration.

Nevertheless, fundamental rights have become more relevant with years in the ECJ case law and in European Union Law. And finally fundamental rights have started to clash with fundamental freedoms. Really, there are two types of relationship between market freedoms and fundamental rights: a positive relationship where fundamental rights serve to protect market freedoms; and a negative one with situations where market freedoms and fundamental rights come into a conflict and ECJ must balance between them.

In the first type of relationship, the most representative cases begin with Elliniki (1991), and continue with Carpenter (2002), and Karner (2004). In these cases, ECJ stipulates that Member States must respect fundamental rights not only when they implement European Law, moreover this respect is also required to practice an exclusion of treaty obligations. Therefore, a measure restricting market freedom must not only be justified, it should also respect fundamental rights as general principles of European Law.

Anyway, a positive synergistic relationship is not a problem to fundamental rights protection. It is in conflicting cases like Schmidberger (2003), Omega (2004), Viking (2007), or Laval (2007), when problems came out. In fact, the question is how ECJ balance between market freedoms and fundamental rights in a conflicting case?

\section{Palabras Clave}

Tribunal de Justicia de la Unión Europea, Derechos Fundamentales, Libertades Económicas

\section{Key Words}

European Court of Justice, Fundamental rights, Economic freedoms. 